\title{
Analyzing the Budgeting Process of Selected Rapid Rail Transit Systems
}

\author{
William D. Cooper \\ L. Milton Glisson \\ Charles F. Malone \\ North Carolina A\&T State University
}

\section{Abstract}

The transportation infrastructure in the United States is entering a period of growth and expansion. During this period of change, attention has been directed toward improving the organizational accountability of the rapid rail transit systems. To date, there has been no definitive study of how rapid rail transit systems integrate the operating budgetary process into decisionmaking or whether doing so would provide greater control over costs. Based on field interviews, this study examines the budgetary processes of 9 of the 13 rapid rail transit systems operating in the United States. Among the areas examined are (1) administrative issues, (2) budgetary planning, (3) frame of reference, (4) investigating variations from plans, and (5) planning feedback. In addition to describing the similarities and differences among the rapid rail transit systems, recommendations and observations are presented.

\section{Introduction}

As we approach the 21 st century, there is a recognized need to maintain, reinforce, and expand the transportation infrastrüeture in the United States. Attention should be directed toward the importance of reinvesting in America's 
capability to move people, transport physical assets, and disseminate information in a more efficient and effective manner. A key component of this vision is a rapid rail transit system that serves large numbers of individuals at a reasonable cost even as it is preparing for future needs.

Both private and public sectors are concerned with organizational accountability. The budgeting process is an important tool for responding to that demand for accountability. Through such a process, an organization can identify objectives and then allocate its resources in a way that will minimize costs and maximize benefits. In light of the foregoing, it might be assumed that strong budgeting procedures would enhance the effectiveness and efficiency of the rapid rail systems. To date, however, no definitive study has been conducted on how rapid rail transit systems integrate the budgetary process into decisionmaking or whether doing so would provide greater control over costs. This paper will identify effective budgetary processes of 9 of the 13 rapid transit systems currently operating in the United States. Its chief objective was to identify effective budgeting procedures that could be adopted by both aging and/or inefficient systems and new and expanding systems. In order to accomplish this objective, this paper includes:

1) a qualitative analysis of the budgetary procedures described by the transit officials during the interviews. The qualitative analysis examines:

- the number and nature of the steps in the budgetary processes of the various transit systems,

- the apparent importance of the processes to the operation of the systems,

- the various systems' methods of dealing with budgetary variances, and

- the systems' use of feedback.

2) conclusions and recommendations concerning the budgeting processes used by the rapid rail transit systems studied.

\section{Background}

According to the U.S. Department of Transportation, Federal Transit Administration, 13 rapid transit rail systems are now operating in the U.S. Due to time and budgetary limitations, it was decided to limit this analysis to 9 rapid rail 
- Metropolitan Atlanta Rapid Transit Authority (MARTA), Atlanta

- Maryland Mass Transit Administration (MTA), Baltimore

- Massachusetts Bay Transportation Authority (MBTA), Boston

- Port Authority Transit Corporation (PATCO), Lindenwold, NJ

- Los Angeles County Metropolitan Transportation Authority (LACMTA)

- Metro-Dade Transit Agency (MDTA), Miami

- Southeastern Pennsylvania Transit Authority (SEPTA), Philadelphia

- San Francisco Bay Area Rapid Transit District (BART), Oakland

- Washington (DC) Metropolitan Area Transit Authority (WMATA)

Figure 1. Rapid rail transit systems included in this study.

transit systems (Figure 1). In addition to the systems identified in Figure 1, rapid rail transit systems are operated by the Chicago Transit Authority, Greater Cleveland Regional Transit Authority, New York City Transit Authority, and the Port Authority Trans-Hudson Corporation.

The systems included were chosen for the following reasons:

- They operate in or near major urban areas.

- They are not so large that their budgetary processes would be too complicated to permit meaningful comparisons among them. (For this reason, the New York and Chicago systems were not included in the study.)

- They have wide geographic dispersion; systems on both East and West coasts were included.

- Some are long-established systems while others are relatively new, thus providing data for analysis that is representative of many, if not all, U.S. systems.

It was further determined that meeting and talking with transit professionals directly involved in the budgetary processes would be the optimal way to obtain the most accurate and complete information about those processes. To make the most of the time spent with each system's personnè and to help collect the information needed for the planned analysis, the researchers created an extensive ques- 
tionnaire. This survey instrument was mailed to a key member of the budgeting department of the selected systems. The recipients of the questionnaire were asked to consider responses to the questions in preparation for an interview to be conducted later in the year. The interviews were held as planned, and tape recordings of the interviews were made with the consent of the agency representatives and later transcribed. During the interviews, additional materials pertaining to the system's budgeting procedures were obtained.

Data about the nine rapid rail transit systems being investigated were subsequently subjected to an intensive qualitative analysis of their budgeting processes. This analysis focused upon the steps involved in the budgetary process, overall complexity/simplicity of the process, and the apparent importance of the process to the system in the organization and methods of dealing with budgetary variances.

\section{Importance of Budgeting}

"Fundamentally, the budgeting process is a method to improve operationsa continuous effort to specify what should be done to get the job completed in the best possible way" (Weston and Brigham 1979: 149). According to Transportation Accounting \& Control, a 1983 report prepared by Ernst \& Whinney, the budgeting process serves three primary functions: planning, control, and communications.

\section{Planning}

The budget is the culmination of an annual planning process, and it documents the resulting plan in financial terms. The plan describes the structured approach necessary for the corporation to meet its goals and objectives, and it helps to ensure that all corporate resources and activities are directed toward a common target.

\section{Control}

The budget provides an objective means to monitor the organization's process in meeting its goals. Inefficiencies and other causes for deviations from the annual plan can be identified by analyzing budget variances. Thus, corrective actions can be taken promptly and can be focused properly when actual results differ from expectations. 


\section{Communications}

The budget provides a communication link between management and those individuals responsible for implementing the plan. Upon completion of the planning process, the budget allocates the firm's scarce resources to management's objectives, goals, strategies, and programs for the next year throughout the organization. During implementation of the plan, monthly budget reports compare actual with planned results to communicate performance measures in a clear, concise format (Ernst \& Whinney 1983: 35).

The Ernst \& Whinney report goes on to list five benefits to be gained from the budgeting process: commonality of goals and objectives, periodic planning, quantification of the plan, effective cost control, performance evaluation (Ernst \& Whinney 1983: 35-36). These benefits are the products of an overall organizational budgetary process. They can be the results obtained if the budgetary process becomes an integral part of the planning process.

\section{Development of Questionnaire and Data Collection}

There is sufficient evidence in the literature to indicate that a researcher attempting to collect primary data has a number of choices to make among the means that will be used. Among those choices is the primary decision of whether to use communication or observation data gathering techniques (Churchill 1987).

Communication involves questioning respondents to secure the desired information, using a data collection instrument called a questionnaire. The questions may be oral or in writing, and the responses may be given in either form. Observation does not involve questioning. Rather, it means that the situation of interest is checked and the relevant facts, actions, or behaviors recorded (Churchill 1987: 224).

Due to the communication method's relative advantages on the versatility, speed, and cost factors, the researchers chose communication as the data collection method for this study. However, selecting CQmmunication as the desired methodology is not as simplistic as it first appears. Beyond the recognition that 
such an instrument is necessary, other data collection decisions are required in at least six other areas regarding the questionnaire. Those areas are degree of structure, degree of disguise, method of administration, sampling control, questionnaire design, and pretesting.

Structure is defined by Churchill (1987) as "the degree of standardization imposed on the data collection instrument." With highly-structured data collection instruments "the questions to be asked and the responses permitted the respondents are completely predetermined" (228). On the other hand, highly unstructured instruments use loosely predetermined questions and individuals are given freedom to select the wording of their answers. This study utilized a relatively highly structured questionnaire. A few of the questions used in the study were open-ended, but the majority of the questions had a fixed set of responses.

Disguised is the amount of knowledge a potential respondent is given about the purpose of a study. An undisguised instrument makes the purpose of the study obvious by the questions posed, whereas a disguised instrument attempts to hide the real purpose of the study (Churchill 1987: 228). This study employed an undisguised instrument. To obtain the cooperation of the transit agencies, it was necessary to explain the purpose of the study. Additionally, it was felt that respondent knowledge would improve the quality of the response particularly with respect to narrowing the focus on the key issues.

Questionnaires are also classified by the method of administration. The major administration methods are mail, phone, and personal interview (Churchill 1987: 241). The method used in this study was a combination of the mail questionnaire and the personal interview. The questionnaire instrument was mailed to each of the respondents several weeks in advance. This allowed the respondent(s) to review the instrument and become familiar with the questions prior to the personal interview. The personal interview was then conducted at a prearranged date and time. As previously noted, most of the questions on the instrument were highly structured, but respondents were allowed to use their own words for answering the open-ended questions and to elaborate on their structured responses. For several systems included in this study, more than one person representing the 
transit organization took part in the personal interview. Although respondents were universally cordial, the extent to which respondents elaborated varied significantly.

Sampling control reflects "the researcher's ability to direct the inquiry to a designated respondent and to get the desired cooperation from that respondent" (Churchill 1987: 242). In the current study, the universe consisted of 13 transit systems. The nine transit systems included in the sample represented 69 percent of that universe. Each of the nine participating transit systems identified the specific respondent(s) to be interviewed and/or to provide additional information and requested materials. The titles, positions, and levels of responsibility of the individuals interviewed varied from system to system. Although for all participating systems the individuals appeared knowledgeable and candid, the differences in responsibilities is a study limitation over which the researchers lacked control.

The researchers used information that was available from independent sources (e.g., Section 15 data), from the participating systems' records (e.g., budget reports and annual budgets), as well as organizational information related to the development and the implementation of the budgetary process.

The questionnaire for this study was pretested on several academic (transportation and non-transportation) faculty and two transportation practitioners in the transit industry. The pretesting process gave the researchers valuable feedback from transit professionals, thereby enhancing the relevance and reliability of the final instrument. The following description of the various sections of the instrument contains several changes made as a result of the pre-testing procedures and incorporated into the questionnaire before mailing it to the transit respondents and subsequently asking the questions during the personal interview.

\section{Administrative Issues}

The first section of the questionnaire contains requests for various descriptive and/or graphic detailed information of each specific transit system. "Budgets quantify future plans of action. A budgeting system builds on historical (actual) performance and expands to include consideration of future (expected) per- 
formance. Budgeting systems turn managers' perspective forward. Financial budgets detail the expected revenue and cost impacts that the organization's plans will have" (Horngren et al. 1994).

Considering the evolution of control systems, it has been found that personal observation is usually the primary means of control in small, new organizations. With experience, managers are able to go beyond mere personal observations by including the organization's historical performance in their analysis. In analyzing past performances, managers learn that they must deal with a longer time horizon, not just a single period. Budgeting is one of the important steps in the growth and improvement of the control system. For instance, a manager would find it useful to compare actual performance in a particular year with the plans developed for that year (Horngren et al. 1994: 182).

By describing the financial plans for the organization's major functions, the master budget consolidates the organization's financial plans and projections. The budget places a dollar value on management's expectations regarding future cash flow, financial position and, of course, income (Horngren et al. 1994). It is readily evident that budgets play a significant role throughout the entire control process. Budgets serve a variety of subfunctions, such as "coordinating activities, implementing plans, communicating, authorizing actions, motivating, controlling, and evaluating performance" (Horngren et al. 1994: 183). However, there are pitfalls or limitations associated with budgeting. Budgeting requires simplifying assumptions that may not capture all aspects of the situation. It is an art, not a science. Frequently, budgeting focuses attention on results without considering the reasons or underlying causes. Additionally, innovations may be curtailed (Helmkamp 1990). If managers have not bought into the benefits to be gained from participative budgeting, they may be unwilling to commit the time and energy necessary to successfully implement budgetary control (Ricketts and Gray 1991; Helmkamp 1990).

According to Horngren et al. (1994), most organizations follow a common budgeting cycle consisting of the following: (1) planning the performance of the organization as a whole as well as its subunits, with the entire management team 
agreeing on what is expected; (2) providing a frame of reference, a set of specific expectations against which actual results can be compared; (3) investigating variations from plans, and, if necessary, following with corrective action; and (4) planning again, considering feedback and changed conditions.

Management decisions in operational areas are concerned with obtaining and using limited resources, while decisions in financial matters center on the identification of sources of funds that will allow the acquisition of necessary resources. The master budget must take into account the effects of both operational and financial decisions.

While implementing a budgeting process has many benefits, the master budget, in and of itself, is not a strategic plan. It is a tool that helps managers implement their strategic plans. Planning consists of more than just budgeting. It has often been recognized that a poor strategic plan that follows the greatest implementation procedure ever devised is doomed to failure. However, an excellent strategic plan poorly implemented will still provide benefits to the organization.

\section{Budgetary Planning}

Budgetary planning is the first phase in the budgeting cycle. During this phase, the management team is forced to plan for changing conditions (Horngren et al. 1994) and to focus on company and departmental goals and objectives. Benefits derived from budgetary planning vary, but include: (a) giving the organization as a whole as well as its subunits an opportunity to influence organizational behavior and (b) providing management a vehicle for anticipating crises that might affect the organization and developing appropriate plans or strategies.

The budgetary planning portion of the questionnaire in this study was designed to addresss three central concerns. First, the researchers wanted to obtain a picture of how each of the nine rapid rail systems develops its budgetary plan. This would entail asking questions about the span of time covered by the budget, the existence of formal guidelines, and various assumptions used to develop the plan. Second, the researchers wanted to determine if the processes used to develop the plans were participative in nature. It was felt that an active involvement by top and middle management in the budgetary planning process would 
lead to a better final product, one that all parties could and would accept (Hilton 1994). Determining the degree of similarities/differences among the systems was the third concern.

\section{How is the Operating Budget Developed?}

The systems' responses to questions related to the development of the master budget are summarized in Table 1 . In addressing the first concern, that of understanding the process, the first four questions of the budgetary planning section of the questionnaire focus on the time frame covered by the budget. As revealed in questions 1 and 2 of Table 1 , all of the rapid rail systems in this study operate on a one-year master budget, and all systems prepare a long-range financial plan.

The systems have differences with regard to the time span covered by the long-range budgetary plan. As shown in question 3 of Table 1 , six of the systems report that their long-range budget covers a period of 10 years or less. Boston, Los Angeles, and San Francisco, however, develop budgetary plans over a longer time horizon. Interestingly, Los Angeles, the newest system in the study, develops its long-range plan on a 30 -year basis, by far the longest of any of the systems.

Question 4, regarding continuous budgeting, was possibly not fully understood by the respondents. Initially, the researchers wanted to determine if a system developed a continuous budget on a monthly basis (sometimes referred to as a "rolling budget"), i.e., a budget that would always be 12 months in advance of the current month. While four respondents indicated that their systems did have continuous budgeting, further discussion suggested that they understood the term differently from what was intended by the researchers. Question 9, regarding the extent to which the system followed formal guidelines, produced some interesting responses. Respondents from all systems except Atlanta indicated that they always or usually follow formal guidelines in developing their budgets. Atlanta's system, however, does not have any formal guidelines but uses a set of documents referred to as a budget call package to complete its budgetary process. Three of the systems "always" follow their formal guidelines. The five respon- 
Table 1

Summary of Responses to Questions Concerning Budgetary Planning

Atl Bal Bos Lin Los Mia Phi San Was

1. Time span of

operating budge

\begin{tabular}{llllllllll}
\multicolumn{1}{c}{ operating budget } & $\mathrm{yr}$ & $\mathrm{yr}$ & $\mathrm{yr}$ & $\mathrm{yr}$ & $\mathrm{yr}$ & $\mathrm{yr}$ & $\mathrm{yr}$ & $\mathrm{yr}$ & $\mathrm{yr}$ \\
\hline 2. Long-range plan? & yes & yes & yes & yes & yes & yes & yes & yes & yes \\
\hline 3. Yrs in long-range plan & $5-10$ & 6 & $5-20$ & $6-14$ & 30 & $3-5$ & 10 & 10 & 5 \\
\hline 4. Continuous budgeting? & no & yes & no & no & no & yes & yes & no & yes \\
\hline
\end{tabular}

5a. Revenue in operating

budget prepared on

centralized basis?

5b. Expense in operating

budget prepared on

centralized basis?

yes yes/no no

no no

no

6a. Can managers submit

estimates of revenue?

yes no yes no yes no yes yes yes

6b. Can managers submit extimates of expenses? yes yes yes yes yes yes yes yes yes

7. Interim revisions in dept. budgets allowed? yes yes yes no yes yes no no yes

8. When are revisions

allowed: at established

points (pts) or whenever

necessary (nec)?

$\begin{array}{llllllll}\text { nec nec . } & \text { pts } & \text { nec } & \text { pts } & \text { pts } & \text { pts } & -- & \text { pts }\end{array}$

9. Formal guidelines

followed? Usually (U)

Always (A), Often (O)

$\mathrm{n} / \mathrm{a} \quad \mathrm{U}$

U A

$\mathrm{U}$

A U

A $\mathrm{U}$

10. Extent of top mgt.

participation in devel-

opment of operating

budget

A $\mathrm{A}$

A A

A

A

O

A A

11. Operating budget approved at all approp.

levels of mgt?

A $\mathrm{A}$

A $\mathrm{A}$

A

A

$\mathrm{O}$

A

A 
Table 1 (continued)

Atl Bal Bos Lin Los Mia Phi San Was

12.Dept. approval required for externally-generated data? Written (W),

Oral $(0)$

$\begin{array}{lllllllll}\mathrm{W} & \mathrm{O} & \mathrm{O} & \mathrm{O} & \text { none } & \mathrm{O} & \mathrm{O} & \mathrm{W} & \mathrm{O}\end{array}$

13. Budget reviewed for completeness and timeliness before approval? yes yes yes yes yes yes yes yes yes

14. How difficult to move line item amounts? Easy (E), Moderately Difficult (MD), Somewhat Difficult (SD), Impossible (I) E $\quad$ E $\quad$ MD I MD $\quad$ E $\quad$ SD $\quad$ I E

15.Primary basis for developing operating budget? (rank in order of importance)

- historical basis

$\begin{array}{lllllllllll}- & - & 2 & 3 & 5 & - & 3 & 6 & -\end{array}$

- historical basis adj. for inflation 2

- historical basis adj. for changes in rider$\begin{array}{lllllllllll}\text { ship, econ. factors, etc. } & 1 & 1 & 1 & 2 & 1 & 1 & 4 & 1 & 1\end{array}$

$\begin{array}{llllllllllll}\text { - statistical models } & 3 & 6 & 4 & 4 & 2 & 4 & 5 & -- & -\end{array}$

$\begin{array}{lllllllllll}\text { - zero-based budgeting } & 4 & 4 & 5 & 2 & 1 & 7 & 2 & -\end{array}$

$\begin{array}{lllllllllll}- \text { executive judgment } & 3 & 2 & 5 & 6 & 3 & 2 & 1 & 3 & -\end{array}$

$\begin{array}{llllllllll}- \text { other } & - & - & - & - & - & - & 3^{*} & - & 4^{* *}\end{array}$

16. Changes require mgt. approval, verbal (V) $\begin{array}{llllllllll}\text { or written (W)? } & \text { W } & \text { V } & \text { W } & \text { no } & \text { W } & \text { V/W } & \text { V/W } & \text { W } & \text { V }\end{array}$

17. Budget process changed $\begin{array}{lllllllll}\text { in last five years? yes yes } & \text { yes no yes no no no yes }\end{array}$

\section{* projected service levels}

** expense budget affected by revenue expectations 
dents that reported that their systems "usually" follow formal guidelines also indicated that some negotiation or variation from suggested protocols takes place.

Questions 12,13, and 16 all concern possible checkpoints in the budget process. Very little variation was noted in the responses to these questions. All systems except Los Angeles require departmental approval of externally generated data, all systems require a review of the budget for completeness and timeliness before its submission for final approval, and all systems but Lindenwold require management approval of changes in budget amounts or methods. Some of the systems use written rather than oral (verbal) checkpoints. The controller at Lindenwold stated that he used his own discretion to make changes and that, in his organization, emphasis is on results rather than on the method of budgeting. It should be noted that Lindenwold is, by far, the smallest transit agency included in the study.

Question 15 tries to identify the primary basis or assumptions used by a system to develop its operating budget. The most important criterion for seven of the nine systems studied is historical cost adjusted for changes in volume of riders, economic factors, prices, etc. However, the Lindenwold respondent identified historical cost adjusted for inflation as the most important factor, while Philadelphia's spokesperson cited zero-based budgeting as SEPTA's primary budget guide. There was less consensus regarding the second most important criterion on which the operating budget is based. Each of the remaining five criteria listed in the questionnaire was chosen by one or more of the respondents as being next in importance to historical cost adjusted for various changes. Similarly, there was no pattern in the criteria identified by the respondents as being third or fourth in importance. It seems that after considering adjusted historical cost to develop their operating budget, each system proceeded on whatever basis it felt most comfortable.

This belief is supported by a review of question 17 , which was concerned with any changes in the budgetary process during the last five years. Respondents from five systems indicated that their organizations had made some changes. While those changes may not have affected basic assumptions, they may, as was the case with Baltimore, reflect a basic change in managerial philosophy. In Bal- 
timore, the budgetary process used to be primarily centralized, i.e., developed by the financial department, but now it is being pushed down to operating units.

In summary:

1) Each system studied prepares a yearly operating budget and operates within a long-range plan.

2) Almost all systems have established formal budget guidelines and, for the most part, follow those guidelines.

3) Almost all systems have checkpoints during their budget planning process when someone's approval is required before the process continues.

4) Historical cost adjusted for various changes is the most important basis for the development of most systems' operating budget.

\section{Is the Budgetary Planning Process Participative in Nature?}

Another concern the researchers wanted to address was the degree to which units within a system participated in the development of the operating budget. "The idea of participative budgeting is to involve employees throughout an organization in the budgetary process. Such participation can give employees the feeling that 'this is our budget,' rather than the all-too-common feeling that 'this is the budget you imposed on us"' (Hilton 1994: 402). Question 5, which asks whether revenue and expense estimates are prepared on a centralized or decentralized basis, revealed two distinct budgetary philosophies. Six systems reported that revenue estimates were developed on a centralized basis. In Lindenwold, for instance, the controller stated that he and the general manager personally develop estimates of ridership and other income-producing activities. The more complex systems, such as Washington, indicated that the budgeting department was responsible for estimating revenue. In contrast to this centralized arrangement, San Francisco's budgeting department gets a great deal of input from other departments in making its revenue estimates: the Planning Department projects ridership, the Finance Department estimates interest revenue, the Real Estate Department estimates revenue from concessions, and the Public Affairs Department predicts advertising revenue. 
The other half of question 5 concerns estimates of expenses. The respondents, for the most part, indicated that expenses were estimated on a decentralized basis. With the exception of Atlanta's MARTA, which uses its Budget Division to estimate expenses, and Baltimore's MTA, which is in a period of transition, all remaining systems rely on a decentralized approach for expense estimation.

Questions 6,10, and 11 further explore the degree to which managers are given opportunity to participate in the budget process. As shown in questions $6 \mathrm{a}$ and $6 \mathrm{~b}$, only three systems deny managers the opportunity to submit revenue estimates for the operating budget, and all systems permit managerial input on estimates of expenses during the development of the budget. As shown in question 11, all systems except Philadelphia always require approval of the operating budget at all appropriate levels of management. Responses to question 10 indicated that, in seven of the systems, top management always participates directly in operating budget preparation, and the remaining two stated that top management participates often.

Questions 7 and 8 indicate that seven systems permit interim revisions in departmental budgets, either at established points or whenever necessary. In the case of Philadelphia, overruns are acknowledged, but the formal budget is not amended. Responses to question 14, which inquires about the difficulty of moving line item amounts, were less consistent. Four respondents noted that it was easy to move line item amounts. In Atlanta and Baltimore, for example, adjusting line items within a departmental budget does not matter as long as departmental totals do not change. On the other hand, the Lindenwold respondent stated that line item changes are "not done in practice," and the San Francisco spokesperson noted that the relative ease or difficulty "depends on the timing of the movement of the line item. Early in the process, it is easy to move line items; later in the budget process, it becomes increasingly difficult."

In summary:

1) Most systems estimate revenue on a centralized basis and expenses on a decentralized basis. 
2) Most systems use some form of participative budgeting, but once the budget is complete, total departmental reallocations cannot be made.

\section{Frame of Reference}

Providing a frame of reference is the second phase in the budgeting cycle. Once a management team has completed budgetary planning, a set of specific expectations against which actual results can be compared must be developed (Horngren et al. 1994). Judging results against budgeted expectations (i.e., against a specific frame of reference) rather than against historical data gives management a clearer picture of an organization's performance, for two reasons. First, when performance is judged on the basis of historical data, inefficiencies buried in past actions may mask corrective efforts. Second, opportunities that did not exist in the past may be ignored in the future (Horngren et al. 1994). Thus, economic or environmental changes that affect current performance would not be used to measure outcomes.

The frame of reference portion of the questionnaire was designed to identify how differences (variances) between budgeted and actual amounts were processed by the various transit systems. To accomplish this, the researchers first asked if those differences were processed in a verbal or written manner for both revenue and expenses. Table 2 summarizes the responses of the participating transit agencies to this portion of the questionnaire. As shown in question 1 of Table 2, all of the systems studied indicated that written explanations would be required for both revenue and expense variances. Some indicated that both memos and summary reports contained within the monthly report were written. Others, such as Atlanta, Lindenwold, and Baltimore, discuss both revenue and expense differences at senior staff meetings, make informal inquiries, and have periodic meetings with operating departments to discuss causes.

Question 2 concerned the internal structure used to discuss differences between budgeted and actual amounts. Conferences were the primary group structure for the transit agencies. Some of these conferences were attended by senior management and department heads only, while others, such as Philadelphia, stated that the deputy general manager, department head, and financial budget analyst 


\section{Table 2}

Summary of Responses to Questions Concerning Frame of Reference

\begin{tabular}{lllllllll}
\hline Atl & Bal Bos Lin Los Man Whi
\end{tabular}

1. Do you have a process for identifying differences between budgeted and actual amounts?

Written (W), verbal (V)

- for revenue

$\begin{array}{llllllllll}\text { V/W } & \text { V/W } & \text { V/W } & \text { V/W } & \mathrm{W} & \mathrm{W} & \mathrm{W} & \mathrm{W} & \mathrm{W}\end{array}$

- for expense

V/W V/W

2. Structure of process: conference (C), oneon-one discussion $(\mathrm{O})$, executive decision (X) $\mathrm{C} / \mathrm{D} \quad \mathrm{C} / \mathrm{D} / \mathrm{X} \quad \mathrm{C} / \mathrm{D}$ C C C D

3. Frequency of review process monthly (M), quarterly $(Q)$, weekly (W), ad hoc (A)

would attend the meetings. Other systems-Atlanta, for example - schedule conferences but also, on a one-on-one basis, have the budget officer contact the affected department for a discussion before any formal conference. Lindenwold does not hold formal conferences focusing on variances but discussion may occur at other meetings. Los Angeles is in a transitional state regarding conferences for the examination of budget variances.

Question 3 queried respondents about the frequency of meetings that focus on budgetary variances. Five systems have regular monthly conferences, Philadelphia holds both weekly and monthly meetings, and Boston meets quarterly. Baltimore currently meets on an ad hoc basis to discuss budget variances but it is moving toward monthly conferences.

In summary:

1) Most of the systems studied require written responses for differences (variances) between budgeted and actual amounts for both revenue and expense. 
2) Most systems require a conference meeting to address differences (variances).

3) Most systems discuss variances on a monthly basis.

\section{Investigating Variations from Plans}

The study's third phase of the budgeting cycle focused on the manner in which the transit systems investigated variations from plans (Horngren et al. 1994). To accomplish this, the researchers identified three primary concerns:

- Does the transit system investigate reasons for budgetary variances?

- Does corrective action take place once variances are identified?

- Does the transit system use budgetary performance to evaluate employees?

Table 3 summarizes responses to questions relating to the investigations of variances from plans. The first question on this portion of the survey instrument asked whether the transit system investigates reasons for budgetary variances. A lack of interest in reasons for variances would indicate a lack of commitment to fulfilling the budgetary process. All of the systems' respondents stated that the reasons for variances are investigated. This indicates that the systems are concerned about the causes of budget variances.

The second question-Does corrective action take place once variances are identified?-focused on one of the principal reasons why organizations study variances. By investigating variations from plans, it is believed that corrective action may follow (Horngren et al. 1994), or at least a better understanding of the variations would be obtained by all parties. All systems in this study indicated that corrective actions were taken when variances were identified. For example, the controller at Lindenwold stated that explanations were obtained if variances were not justified, while Baltimore's deputy finance director stated that corrective action would depend on the reason for the variance.

Questions 3 and 4 (Does the transit system, either on a formal or informal basis, use budgetary performance to evaluate employees?) tried to determine if budgetary performance had any impact on employee evaluation. The researchers felt that the operating budget quantifies the goals and expectations of management, and that it is a better comparative basis for evaluating any employee's 


\section{Table 3}

\section{Summary of Responses to Questions Investigating}

Variances from Plans

\begin{tabular}{lllllllllll}
\hline & Atl & Bal & Bos & Lin & Los & Mia & Phi & San & Was \\
\hline $\begin{array}{l}\text { 1. Are reasons for variances } \\
\text { investigated? }\end{array}$ yes & yes & yes & yes & yes & yes & yes & yes & yes \\
\hline $\begin{array}{l}\text { 2. Is corrective action taken? yes } \\
\text { yes }\end{array}$ & yes & yes & yes & yes & yes & yes & yes \\
\hline
\end{tabular}

3. Formal relationship between performance and bonuses, salary, or

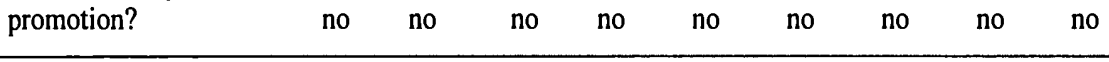

4. Informal relationship between budget performance and bonuses, salary, or promotion? yes no maybe no no yes no no no

5. Termination, demotion, transfer, salary reduction, or other adverse effects of failure to meet budget expectations?

no no maybe no no no no no no

6. Frequency of adverse effects? never $(\mathrm{N})$, $\begin{array}{llllllllllll}\operatorname{rarely}(\mathrm{R}), \text { often (O) } & \mathrm{N} & \mathrm{R} / \mathrm{N} & \mathrm{R} & \mathrm{N} & \mathrm{N} & \mathrm{O} & \mathrm{R} & \mathrm{N} & \mathrm{N}\end{array}$

7. Assessment of budgetary meeting in organization? essential (E), very essential (VE), somewhat useful (SU)

performance than past performance (Ricketts and Gray 1991). For the most part, representatives of the systems studied stated that there were no formal or informal relationships between employee evaluation and budgetary expectations. There were, however, some notable exceptions and comments. In Atlanta and Miami, for example, an informal relationship may exist that would influence employee salary and promotion. Furthermore, some respondents who stated that their sys- 
tem did not relate budgetary performance to employee evaluation did, however, indicate that such a process would be useful.

When asked about the effect of failure to meet budget expectations on employee termination, demotion, or transfer, most indicated that there were no adverse consequences. Only Boston's representative stated that there "could be" a correlation between the two. The respondent from Philadelphia stated it best when he said that it was "not clear that there are any adverse effects." As shown in question 7 of Table 3 , when asked to assess the importance of budgetary meetings to their organization, most of the respondents characterized the meetings as "very essential." Due to the recent merger of transit agencies to form the LACMTA, the importance of the budgetary meetings in Los Angeles is undergoing change.

In summary:

1) All transit systems included in this study investigate reasons for variances and take corrective action.

2) No formal relationship exists in any system between good budgetary performance and incentive pay, salary, or promotion.

3) Only in some systems does even an informal relationship exist between good budgetary performance and incentive pay, salary, or promotion.

4) Transit officials do not experience adverse consequences for failure to meet budget expectations.

\section{Planning Feedback}

The fourth and final phase in the budgeting cycle that was studied focused on how the rapid transit system analyzed the budgeting process--feedback (Horngren et al. 1994). Feedback, unlike variance analysis, "involves the whole decision system, [it] is the process of studying the system to improve it" (Needles 1992: 6). Rather than concentrate on short-term problems facing the organization, feedback looks at long-term difficulties. "Feedback may convince the decision maker that the prediction method, rather than the implementation, was faulty" (Horngren et al., 1994: 387-388). Organizations often fail to consider feedback or changing conditions before entering the next budgetary planning cycle. For example, the management team may not relate organizational goals to budgetary 
planning. This, in turn, could lead to a budgetary process that is proceduralistic in nature, one that fails to become the central planning tool that it was intended to become.

In order to determine if information from the budgetary process was being fed back into the planning cycle, three questions were asked in the survey instrument. Table 4 summarizes the responses to the questions concerning feedback. The researchers first wanted to determine the frequency in which the operating budget was reviewed. Five of the transit systems preferred to review the operating budget on a monthly basis. Atlanta indicated that budgetary procedures were discussed at senior staff review meetings. The two systems that review the operating budget on a quarterly basis (Boston and Baltimore) indicated that they may move toward more frequent scheduling. One of the two remaining systems, Lindenwold, stated that the system is reviewed annually on an overall basis, but that departments conduct monthly reviews for their own use. Finally, Miami reviews its budget on a continuous basis.

Respondents from the various transit agencies were asked to rank the importance of several factors on the development of the operating budget. As can be seen in question 2 of Table 4 , there was no unanimity among the respondents, and this may very well reflect differences in the economic and political situations confronting the transit agencies. The cost-benefit factor was ranked number one by four agencies, more than any other factor. Three agencies selected revenues as the most important factor, and political considerations were primary in the remaining agencies. It should be noted that eight of the nine agencies ranked revenues among the top three factors. Political considerations were among the top three factors in six of the agencies. Cost-benefit and social needs were the only other factors ranked among the top three by four or more agencies. Respondents were given the opportunity to identify and rank factors not specified on the questionnaire. The only two additional factors identified were "new construction" by Boston's MBTA and "service levels" by Miami. Two of the systems ranked less than six factors as having an impact on the operating budget development. Also, 


\section{Table 4}

Summary of Responses to Questions Concerning Feedback

Atl Bal Bos Lin Los Mia Phi San Was

1. How often is operating budget reviewed?

monthly (M), quarterly

(Q), annually (A), continuously $(\mathrm{C})$

M Q

Q

A

M

C

$M \quad M \quad M$

2. Impact of various factors on development of operating budget (ranked in order of importance):

- revenues

- cost benefit

- social needs

- politics

- demographic trends

- technology

3. Does budgetary planning help achieve organizational goals?

if one were to assign equal values to non-ranked factors and determine the mean rank, revenues was the most influential factor followed by cost-benefit and politics.

The final question concerning feedback focused on whether the budgetary planning process helped to achieve organizational goals. As can been seen in question 3 , all of the respondents indicated that they believed their current budgetary process assists them in achieving organizational goals.

In summary:

1) Most of the systems review the operating budget on a monthly basis.

2) Revenues, cost-benefit, and political considerations tend to be the most influential factors affecting the development of the operating budget. 
3) The budgetary planning process is perceived as being helpful in all of the systems for the achievement of organizational goals.

\section{Conclusions and Recommendations}

The primary objective of this study was to identify effective planning and budgeting procedures that older existing systems could adapt and newer systems could implement. It is intended that heavy rail general managers, financial officers, policy and planning personnel, and other individuals and organizations that are affected by heavy rail services will find this report to be useful. This report explored current practices within selected heavy rail systems noting the linkages between financial measurement, budgetary planning and practices, and performance measurement.

At the start of every fiscal year, budgetary officers begin a process referred to as "developing the budget." Starting with a set of documents, frequently identified as a "Budget Call Package," the Budget Director initiates the budgetary process, requiring the various departments to complete certain portions of the package at stated times. Is this approach reasonable or adequate for the transit system? Unfortunately, information concerning budgeting is scattered in a variety of accounting and budgetary publications and, as a consequence, it is difficult to obtain a clear consensus to problems. This report attempts to address this problem by synthesizing current practices used within the heavy rail industry and makes recommendations for possible improvement.

Managers are taking a closer look at budget variances in order to understand their causes and, if possible, to implement corrective actions. Some systems are considering the development of meaningful standards upon which individuals will be judged as to their performance and accountability for budgetary variances. This may become a necessity because funding agencies are requiring transportation entities to become more cost effective. It is recognized that transit systems require varying degrees of funding support. Moreover, transit systems have been operating in an increasingly austere environment as their allocations from funding sources have been constantly reducèd as governments move to- 
ward balanced budgets. Although there are limitations to a budgetary process, based on the results of this stady the following recommendations can be made:

1) Transit systems should explore the potential of developing a greater relationship between budgetary performance and performance evaluation.

2) It was observed that approximately one-half of the systems in the study allowed liberal transfer of budgetary amounts between line items.

3) All systems should consider using a participative approach in the development of budgets.

4) All systems should develop yearly budgets and a set of detailed budgetary procedures.

5) Checkpoints should be developed during the budgetary planning process where appropriate official approval is required before the process continues.

6) Given the consistent approach of the systems in the study, other transit systems should consider centralized revenue estimation while estimating expenses on a decentralized basis.

7) Identification and discussion of material differences (variances) between budgeted and actual amounts for both revenue and expenses should be routinely carried out.

\section{References}

Churchill, G. A., Jr. 1987. Marketing Research: Methodological Foundations. The Dryden Press.

Dotter, L. A. 1994. Washington Metropolitan Area Transit Authority, Office of Budget and Management Analysis, Washington, D. C., interview, July 28, 1994.

Ernst \& Whinney. 1983. Transportation Accounting \& Control: Guidelines for Distribution and Financial Management. National Council of Physical Distribution Management, Oak Brook, IL.

Helmkamp, J. G. 1990. Managerial Accounting. New York: John Wiley \& Sons. Hilton, R. W. 1994. Managerial Accounting. New York: McGraw-Hill, Inc. Horngren, C. T., G. Foster, and S. M. Datar. 1994. Cost Accounting: A Managerial Emphasis. Englewood Cliffs, NJ: Prentice-Hall. 
Needles, B. E., Jr. 1992. Financial Accounting. Boston: Houghton Mifflin Company.

Ricketts, D., and J. Gray. 1991. Managerial Accounting. Boston: Houghton Mifflin Company.

Stockton, J. R. 1966. Introduction to Business and Economic Statistics. Cincinnati, OH: South-Western Publishing Company.

Weston, J. F., and E. F. Brigham. 1979. Essentials of Managerial Finance. Hinsdale, IL: The Dryden Press.

\section{About the Authors}

William D. Cooper, C.P.A., Ph.D., is Professor of Accounting in the School of Business \& Economics at North Carolina A\&T State University in Greensboro. L. MitroN GuIsson, Ph.D., is Professor of Marketing and Transportation in the School of Business \& Economics at North Carolina A\&T State University in Greensboro. Charles F. MALONE, C.P.A., J.D., Ph.D., is Associate Professor of Accounting in the School of Business \& Economics at North Carolina A\&T State University in Greensboro. 